\title{
Rules We Live by: How Religious Beliefs Relate to Compliance with Precautionary Measures Against COVID-19 in Tibetan Buddhists
}

\author{
Heng $\mathrm{Li}^{1} \cdot \mathrm{Yu} \mathrm{Cao}^{2}$
}

Accepted: 18 January 2022 / Published online: 5 February 2022

(c) The Author(s), under exclusive licence to Springer Science+Business Media, LLC, part of Springer Nature 2022

\begin{abstract}
The present studies investigated how particular religious beliefs shape compliance with preventive measures in adherents of Gelug and Nyingma schools of Tibetan Buddhism. In Study 1, Gelug and Nyingma monks were asked to report their compliance with various infection prevention measures surrounding COVID-19. Results showed that the former group showed higher compliance with public health guidelines than the latter. Extending beyond self-report measures, Study 2 added a behavioral outcome measure and observed the same effect. Together, our results provide the first empirical evidence that various Tibetan Buddhist traditions are related to different degrees of compliance with precautionary measures against COVID-19.
\end{abstract}

Keywords COVID-19 · Tibetan Buddhism · Precautionary measures · Gelug · Nyingma $\cdot$ Religious beliefs $\cdot$ Behavioral outcome

\section{Introduction}

The new coronavirus disease (COVID-19) has severely affected the global economy (Susskind \& Vines, 2020), health systems (Driggin et al., 2020), as well as international and domestic politics (Greer et al., 2020). The development of new, safe, and effective COVID-19 vaccines brings renewed hope to end the pandemic. Despite mass vaccination helping multiple countries make significant strides in the fight against COVID-19, public health officials worldwide recommend that people still need to wear a mask, follow social distancing measures, and practice good hand hygiene even after they have been fully vaccinated (Buckner et al., 2021; Shen et al.,

Heng Li

leehem168@163.com

1 College of International Studies, Southwest University, Chongqing 400715, China

2 School of Foreign Languages, Zhongnan University of Economics and Law, Wuhan, China 
2021). Thus, understanding why individuals comply with or flout public health recommendations is critically important for stopping the circulation of the virus during the pandemic. In the literature, health psychologists have placed great value on the power of health risk factors and health interventions (Murphy et al., 2020; Xie et al., 2020), whereas social psychologists have stressed the roles of stable personality traits (e.g., the Big Five and Dark Triad traits) and of individual differences in other psychological constructs (e.g., entitlement, empathy, and optimism) (e.g., Li, 2021a; Ludeke et al., 2021; Triberti et al., 2021), in predicting preventive behavior.

\section{Cultural Differences in Adherence to COVID-19 Protocols}

The recent burgeoning literature has documented cultural variation in adherence to COVID-19 safety and health protocols across the world (Deopa \& Fortunato, 2021). For instance, leveraging a dataset of the Google COVID-19 community mobility reports and the Hofstede cultural factors, Huynh (2020) investigated cultural differences with regard to proxemic behavior across 58 countries. It was found that uncertainty avoidance is a significant predictor in explaining many control measures, such as avoiding large events and gatherings under the COVID-19 pandemic, even accounting for potential explanatory variables such as the wealth status and GDP per capita. This pattern of results highlights the important role of culture in infection prevention behavior.

Even though culture is likely to influence how people tackle the COVID-19 crisis, cultural context is difficult to capture and can be defined in many ways (Hofstede, 2001). For example, a long research tradition in cross-cultural psychology studies is to focus on the East versus West divide, like between US Americans in relation to Japanese (Triandis, 1999). Despite these two cultures differing in a host of ways, they also share some prominent characteristics such as high levels of individualism and low levels of collectivism (Takano \& Osaka, 1999), which may significantly relate to preventive measures surrounding COVID-19 (Huang et al., 2020). In a recent series of large-scale studies, Lu et al. (2021) empirically examined whether the collectivism dimension of culture can predict mask usage, a mitigation strategy critical for thwarting the spread of COVID-19. Utilizing data involving 3,141 counties of the 50 US states, 367,109 participants in 29 countries and areas, and 277,219 Facebook users in 67 countries, they found that in comparison to people from regions characterized by individualism, people from regions characterized by collectivism were more likely to engage in face wearing behavior. These findings suggest that the individualism-collectivism dimension of culture is a consistent and robust predictor of compliance with protective measures in the current pandemic.

\section{Religious Responses to COVID-19}

In addition to individualistic/collectivistic orientations, religion is also an important yet an often-overlooked dimension of culture in past research (Richardson \& Mueller, 2019; Tarakeshwar et al., 2003). In the current inquiry, we argue that religious 
systems should be fully integrated into research on cross-cultural differences in compliance with COVID-19 advice for the public. In the literature, religion is commonly defined as a socio-cultural system of shared values, practices, and rituals that relates human communities to sacred, supernatural, and spiritual realms (Geertz, 1966; Nongbri, 2013; Vishkin et al., 2021). Decades of studies have demonstrated that religious systems have a substantial impact on perceptual, cognitive, and emotional brain processes (Li \& Cao, 2018; Wuthnow, 2007). For instance, researchers have found that religious beliefs change attentional and action control processes (Colzato et al., 2010), modulate intertemporal choice (Paglieri et al., 2013), and enhance healthy emotion regulation (Vishkin, 2021).

Research is only starting to document the varying roles of religion in global response to the COVID-19 pandemic (Quadri, 2020; Wildman et al., 2020). In a systematic review, Lee et al. (2021) found that compared to atheists, religious people were less likely to abide by social distancing rules. For example, Agley (2020) demonstrated that religious commitment was negatively correlated with overall trust in science and scientists in a sample of 242 US-based Amazon Mechanical Turk users. Along the same line, Hill et al. (2020) found that more religious states in the USA showed a higher mobility and more resistance to COVID-19 advice for the public such as sheltering-in-place. Overall, these findings suggest that religion seems to exert mostly negative impacts on adherence to precautionary measures against COVID-19.

As reviewed above, most studies have discussed how religious gatherings present a risk for increasing the spread of COVID-19 and documented the positive relationship between religiosity and foment mistrust toward science and public health recommendations. However, these studies on religion and health have several limitations. First, despite religious adherents (vs. atheists) showing more resistance to health care directives, it is unclear how particular religious beliefs shape followers' response to the coronavirus pandemic. Second, a vast majority of studies focused primarily on the Abrahamic faiths, which left an unanswered question regarding the generalizability of these findings in non-Abrahamic religions (e.g., Buddhism and Taoism). Finally, virtually all studies on preventive measures relied on self-report instruments, which may present difficulties to translate these findings into applications. To address these issues, in this article, we studied whether religion-related differences are associated with adherence to precautionary measures surrounding COVID-19 by comparing monks of the Gelug and Nyingma sects in Tibetan Buddhism.

\section{Impact of Tibetan Buddhism on COVID-19 Cognitions}

The Gelug school of Tibetan Buddhism is the newest and emerged as the most powerful institution in Tibet. It was founded in the 15th century with the construction of the Gandan Temple in Lhasa by the Tibetan religious leader Tsongkhapa (1357-1419). The term Gelug literally means "good at self-constraint" in the Tibetan language. The Gelug monks are required to cultivate extreme self-discipline on a daily basis since the Gelugpa lineage attaches special importance to strict observance of the Buddhism law 
and religious discipline (Humphreys, 2005). This doctrine is in opposition to monastic bad behavior that had been rehearsed by many depraved monks who sought pleasure of riches and fame, fought for power, and generally acted without considering the wellbeing of ordinary people (Wang, 2016). This positive standard of saving common people helped the Gelug sect gain great popularity in history. The Nyingma, which means "ancient" in the Tibetan language, is the oldest and the second largest lineage of Tibetan Buddhism. It has roots going back to the 8th century when Bön was still the predominant spiritual tradition in Tibet (Rinpoche et al., 1991). The Nyingma sect puts emphasis particularly on utilizing all facets of life as avenues especially meditation to pure awareness. For example, Nyingma practitioners can make use of rituals, symbols, and tantric practices to reach Buddhahood (Sherab \& Dongyal, 2010).

The traditions of strictly abiding by religious disciplines in the Gelug sec of Tibetan Buddhism led us to speculate that following a set of religious rules might indeed result in more compliance with preventive measures even though these coronavirus rules are unrelated to rule-follow practice taught by religious traditions. Prior work regarding the effect of religious practice on cognition offered supporting evidence for this idea. For example, Colzato et al. (2010) found that rule-following practice biased the way religious adherents attend to and process non-religious visual stimuli. Specifically, Calvinists, who focus strongly on individual responsibility, showed a reduced global precedence effect. In contrast, Roman Catholics and Orthodox Jews, who place a great emphasis on social solidarity, showed an enhanced global precedence effect. Such findings suggest that religious training may cause members of different religions to adopt different cognitive-control strategies and develop default function parameters that extend to non-religious contexts.

\section{Overview of The Present Research}

To test whether strictness to religious rules can generalize to strict observance of COVID protocols, we compared Gelug and Nyingma monks who share a national identity, ethnicity, and language and yet vary in their rule-following practice. This "just minimal difference" approach allows us to focus on the religious difference of interest while holding constant as many extraneous variables as possible (Cao \& $\mathrm{Li}, 2021$; $\mathrm{Li}$, 2021b; Li \& Cao, 2019; Uskul et al., 2008). In Study 1, we asked participants to report to what extent they acted in accordance with COVID-19 prevention guidelines. Study 2 sought to determine if the observed effect is reliable in a behavioral encounter. In both studies, we decided in advance to recruit as many eligible participants as we could over a two-week time period of data collection to reduce the risk of researcher degree of freedom. 
Table 1 Demographic characteristics and religious behavior of participants in Study 1 (standard deviations are presented within parentheses)

\begin{tabular}{lll}
\hline Sample & Gelugpa monks & Nyingma monks \\
\hline $\mathrm{N}$ (M: F) & $110(110: 0)$ & $103(103: 0)$ \\
Age & $45.8(9.6)$ & $47.6(9.9)$ \\
Years of education & $14.3(1.5)$ & $13.9(1.4)$ \\
Members of the Gelug lineage (Yes: No) & $110: 0$ & $0: 103$ \\
Members of the Nyingma lineage (Yes: No) & $0: 110$ & $103: 0$ \\
Actively follow the Gelug tradition (Yes: No) & $110: 0$ & $0: 103$ \\
Actively follow the Nyingma tradition (Yes: No) & $0: 110$ & $103: 0$ \\
\hline
\end{tabular}

\section{Study 1}

\section{Method}

Participants Participants were recruited from Tibetan monasteries and temples in Shannan Prefecture, which is located in the southern part of the Tibet Autonomous Region of China. They were enrolled for a multistage study project ${ }^{1}$ concerning religion and cognition. Their daily activities include discussion of Tibetan Buddhist teachings, Buddhist rituals and initiations, mantras and meditation practice. Since Nyingma monks were relatively hard-to-reach populations (the total number of believers is lower than the number of Gelug monks in Tibet), the researchers first recruited Nyingma monks. Subsequently, Gelug monks who were closely matched with Nyingma monks in terms of demographic variables were recruited.

The Gelug group consisted of 110 people and the Nyingma group consisted of 103 people. All participants were matched for ethnicity (100\% Tibetans), culture (100\% Tibetan), age, gender, and education background-see Table 1 for demographic information and religious practice. Since Tibetan Buddhists cannot receive monetary reward for their participation and cooperation in the research, we donated 10 -yuan RMB for each religious participant to the monasteries which they were affiliated with.

\section{Materials and Procedure (Study 1)}

Participants took part in the survey after providing informed consent. First, the participants were questioned about their religious affiliation, age, sex, ethnicity, and educational attainment. Then, they were instructed to complete a questionnaire about engagement in preventive measures to contain the spread of COVID-19. The six generic precaution measures (maintaining social distancing, wearing masks/face

\footnotetext{
1 In this multistage project, participants were asked to complete a time management survey and a reaction time task about spatial representations of abstract concepts. Both of them are unrelated to people's health behavior and decision.
} 
Table 2 Summary of results of Study $1(N=213)$

\begin{tabular}{lllll}
\hline Variable & Gelugpa monks & Nyingma monks & \multicolumn{2}{l}{ Comparison } \\
\cline { 4 - 5 } & $M(S D)$ & $M(S D)$ & $t(1,211)$ & $p$ \\
\hline Social distancing & $3.32(1.31)$ & $2.92(1.37)$ & 2.18 & 0.031 \\
Wearing masks & $3.56(1.18)$ & $3.12(1.33)$ & 2.56 & 0.011 \\
Respiratory etiquettes & $3.35(1.23)$ & $2.98(1.28)$ & 2.15 & 0.033 \\
Self-monitoring of health & $3.10(1.28)$ & $2.73(1.39)$ & 2.02 & 0.044 \\
Hand washing & $3.24(1.20)$ & $2.84(1.41)$ & 2.23 & 0.027 \\
Prohibiting spitting & $3.11(1.25)$ & $2.72(1.37)$ & 2.17 & 0.031 \\
\hline
\end{tabular}

covers, following respiratory etiquettes, self-monitoring of health and reporting any illness at the earliest opportunity, practicing frequent hand washing, and prohibiting spitting) were issued by the Tibet Autonomous Regional People's Government. Tibetan Buddhists were required to rigorously follow these standard precautionary measures in religious places and places of worship.

Participants were asked to indicate their adherence to these COVID-19 guidelines on a 5-point Likert scale ranging from Not At All (1) to Always (5). The Cronbach's alpha was 0.80 , which suggests that the questionnaire has satisfactory internal validity. Items were averaged to create an index of compliance with these precautionary measures. Finally, participants received the funnel debriefing in which they were asked about the true purpose of the study. Once funnel debriefed, participants were fully debriefed and thanked for their participation.

\section{Results and Discussion (Study 1)}

Analyses of the funneled debriefings indicated that no participants were aware of the true nature of the study. In line with our prediction, Gelugpa lineage practitioners reported higher compliance with COVID-19 preventive and control measures $(M=3.28, S D=0.78)$ than Nyingma lineage practitioners $(M=2.89, S D=0.55)$, $t(211)=4.25, p<0.001$, Cohen's $d=0.57,95 \%$ confidence interval $[\mathrm{CI}]=[0.2109$, 0.5764]. In addition, significant differences were obtained regarding single-item measures of compliance with public health guidelines as shown in Table 2.

Although the interpretation of results from single-item measures should be made with caution because of their dubious reliability and validity (Cronbach \& Meehl, 1955), these findings provided preliminary evidence that the overall levels of implementing COVID-19 guidelines in Gelug monks were significantly higher than the overall levels of Nyingma monks. One reason for this difference may be associated with the strictness of religious practices. To further substantiate these findings, we conducted a second study to provide a behavioral choice confirmation of the observed variation. Specifically, we examined whether religious participants abide by a laboratory hygiene rule- practicing hand washing before entering the experimental room as requested. 
Table 3 Demographic characteristics and religious behavior of participants in Study 1 (standard deviations are presented within parentheses)

\begin{tabular}{lll}
\hline Sample & Gelugpa monks & Nyingma monks \\
\hline $\mathrm{N}(\mathrm{M}: \mathrm{F})$ & $98(98: 0)$ & $86(86: 0)$ \\
Age & $40.8(8.7)$ & $41.4(8.2)$ \\
Years of education & $12.9(1.4)$ & $12.6(1.0)$ \\
Members of Gelug lineage (Yes: No) & $98: 0$ & $0: 86$ \\
Members of Nyingma lineage (Yes: No) & $0: 98$ & $86: 0$ \\
Actively follow the Gelug tradition (Yes: No) & $98: 0$ & $0: 86$ \\
Actively follow the Nyingma tradition (Yes: No) & $0: 98$ & $86: 0$ \\
\hline
\end{tabular}

\section{Study 2}

\section{Method}

Participants Participants were recruited from Tibetan monasteries and temples in Shannan Prefecture as in Study 1. The Gelug group consisted of 98 people and the Nyingma group consisted of 86 people. All participants were matched for ethnicity (100\% Tibetans), culture (100\% Tibetan), age, gender, and education backgroundsee Table 3 for demographic information and religious practice. Since Tibetan Buddhists cannot receive monetary reward for their participation and cooperation in the research, we donated 15-yuan RMB for each religious participant to the monasteries which they were affiliated with.

\section{Materials and Procedure (Study 2)}

Participants took part in the survey after providing informed consent. Following Li (2021a, 2021b), we used a confederate who was blind to the true reasoning and hypothesis behind the study. The naïve confederate met participants in the lobby of a building. The confederate greeted the participants and gave an overview of the study which was purported to be a cultural knowledge test. In addition, participants were informed that they needed to walk down the stairs to the experiment room which was located at the third floor. To curb the impact of the coronavirus, a hand sanitizer dispenser was placed approximately 15 feet to the left or right of the door (the location of the hand sanitizer dispenser was fully counterbalanced across participants). Participants were requested to wash and sanitize their hands to protect themselves from COVID-19 before entering the experimental room. Another confederate at the reception desk wrote down whether the participants practiced handwashing or not without drawing their attention.

After they entered the laboratory room, participants were instructed to complete a cultural knowledge test which is unrelated to the main purpose of the study and a demographic questionnaire. Finally, participants received the funnel debriefing in which they were asked about the true purpose of the study. Once funnel debriefed, participants were fully debriefed, thanked for their participation, and dismissed. 


\section{Results and Discussion (Study 2)}

All participants correctly recalled personal hygiene tips regarding applying an amount of hand sanitizer to clean hands before walking into the experimental room. Analyses of the funneled debriefings indicated that no participants were aware of the true nature of the study. We found that a majority of Gelug monks (66 of 98 or $67.3 \%$ ) cleaned their hands as requested at a rate that was statistically higher than $50 \%, \chi 2(1, N=98)=11.79, p<0.001$, Cramer's $V=0.35,95 \% \mathrm{CI}=[0.1542,0.5143]$. About a half of Nyingma monks (41 of 86 or 47.7\%) cleaned their hands as requested at a rate that did not significantly differ from $50 \%, \chi^{2}(1, N=203)=0.19, p=0.67$, Cramer's $V=0.047,95 \% \mathrm{CI}=[-0.1635,0.2525]$. To determine whether there was a difference in compliance with hygiene rules between Gelug and Nyingma monks, we ran a binary logistic regression (Logit) with hand hygiene behaviors (washing hands $=1$ vs. not washing hands $=0$ ) as the dependent variable. As predicted, Gelug practitioners were more likely to follow the hand hygiene guideline than Nyingma practitioners, Nagelkerke $R^{2}=0.05$, Wald $(\mathrm{df}=1)=7.18, p=0.007$, odds ratio $=2.26$ (95\% confidence interval $[\mathrm{CI}]=1.245,4.116)$.

\section{General Discussion}

Our study showed that practitioners of different sects of Tibetan Buddhism differed significantly and systematically in their response to the COVID-19 pandemic. In Study 1, we showed that Gelug and Nyingma monks with extreme beliefs reported different levels of compliance with enforcement measures like wearing mask, social distancing, and hand hygiene. In Study 2, participants were requested to wash their hands before entering the laboratory room. Gelug adherents were more likely to practice hand washing than Nyingma adherents, which provides a behavioral choice confirmation of the observed variation. Thus, we offered robust evidence that religious beliefs are related to different degrees of compliance with precautionary measures against COVID-19 in Tibetan Buddhists.

There can be no denying that the Gelug and Nyingma schools of Tibetan Buddhism differ in various aspects. More importantly, many of those differences may contribute to the different levels of adherence to public health recommendations. However, an import strength of the present research is that it examined two religious communities based on the same geographic location, ethnicity, language background, and national region and yet vary in their strictness to religious practice. Though the acquired data derived from a cross-sectional and correlational study, the "just minimal difference" approach sheds some light on the perennial challenge of causality problem in cultural/religious studies (Li \& Cao, 2019; Uskul et al., 2008). It may suggest that religious systems can have a reliable impact on compliance to community mitigation decisions rather than other extraneous factors that may be responsible for this observed variation.

Thus, we would argue that the strong focus on strict adherence to monastic discipline and scholarship in Gelug tradition may translate into a high emphasis on 
compliance with health guidelines in the context of COVID-19. This pattern of results is in agreement with previous findings that members of religious communities are cognitively shaped by their religious beliefs (Colzato et al., 2010). For instance, Oyserman et al. (2002) proposed that the legacy of the Protestant work ethic and its attitude might foster North American individualism, which suggests that religion is influencing ways of thinking and, in combination with the current findings, might also influence health decision-making.

The quasi-experimental method raises some concerns about possible alternative explanations to the results, however. For example, some critics may argue that the Gelug school of Tibetan Buddhism is more attractive for highly disciplined people than the Nyingma lineage. If this is the case, our findings could be due to self-selection bias rather than the influence of religious beliefs. However, there is reason to think that self-selection bias does not hold much promise as a viable explanation of the observed difference. This is because Tibetan Buddhism encourages parents to involve their children in the life of a Buddhist monastery. Thus, Tibetan people commonly join the monastic order from early childhood by following family traditions.

An additional noteworthy finding is that the overall compliance level with COVID-19 preventive and control measures was relatively low in different sects of Tibetan Buddhism. For example, less than a half of Nyingma monks (47.7\%) followed the laboratory hygiene rules in Study 2. We proposed several explanations for this result. First, China has managed to control the pandemic effectively and no confirmed case was in this area when the studies took place. Thus, people may feel it unnecessary to strictly follow those coronavirus precautions to prevent COVID19. Second, the Tibet Autonomous Region imposed strict coronavirus restrictions such as requiring visitors to provide negative nucleic acid results within forty-eight hours upon arrival. Third, some research has shown that religiosity promotes passive forms of immoral behavior in which individuals engage in an act that helps them but harms others (Shariff \& Norenzayan, 2011). For instance, Jackson and Gray (2019) found that cars with religious decorations were more likely to park poorly than cars with secular decorations. In a similar vein, breaching coronavirus restrictions is also a clear example of passive immorality because people do not actively spread the virus-just passively not wearing masks or breaking social distancing rules for personal convenience.

Taken together, our findings are important and have meaningful theoretical and practical implications. Theoretically, the results of the current studies suggest that religious practice may have lasting consequences for health behavior in response to COVID-19 crisis. This general conclusion is consistent with an earlier study by Nisbett and Miyamoto (2005), who found that any practice associated with following a code of conduct can sufficiently trigger corresponding changes in other inspired practice even if it bears little relevance to the original domain. More generally, our research joins a burgeoning literature on the cultural determinant of preventive behavior toward COVID-19 (Huynh, 2020), even though we note that virtually all studies ignored the impact of particular religious beliefs such as Tibetan Buddhism on health behavior.

In practical terms, religious organizations were considered as spaces for the diffusion of fake news about COVID-19 which further cultivated mistrust toward health 
professionals and health care initiatives among religious followers of these institutions (Agley, 2020). In addition, there were several cases where religious gatherings and practices were responsible for spreading the coronavirus since religious adherents failed to abide by social distancing recommendations (Lee et al., 2021). Our results also suggest that Tibetan Buddhists showed relatively low compliance with public health guidelines. Thus, special measures, such as public safety campaigns and displaying posters/standees on health guidelines, must be taken to raise awareness about precautionary measures among religious communities.

\section{Study Limitations}

The present research does have limitations which open up a wealth of possibilities for future research. To begin with, despite a careful matching process increasing our confidence that religious beliefs drive the difference in following public health advice between these two religious groups, future researchers should employ an experimental design that uses religious priming to explore the causal effect (Pichon et al., 2007). Second, although we connected specific theological themes with coronavirus-related public health behavior in a real-context, the current study only investigated Tibetan Buddhists. Thus, we should exercise caution about generalization of these findings and explore the proposed effect of religious beliefs among diverse populations in future studies. Last but not least, the current research has focused on the impact of theology in general and has not considered if personality and individual differences may moderate the observed effect (Cao \& Li, 2022). Therefore, individual differences should be integrated into the study to capture a more complete understanding of the role of religious systems in influencing health decision-making.

Funding The authors have not disclosed any funding.

Data Availability The data that support the findings of this study are available from the corresponding author upon reasonable request.

\section{Declarations}

Conflict of interest The authors declare that they have no conflict of interest.

Ethical Approval All procedures performed in studies involving human participants were in accordance with the ethical standards of the institutional and/or national research committee and with the 1964 Helsinki declaration and its later amendments or comparable ethical standards.

Informed Consent Informed consent was obtained from all participants. 


\section{References}

Agley, J. (2020). Assessing changes in US public trust in science amid the COVID-19 pandemic. Public Health, 183, 122-125. https://doi.org/10.1016/j.puhe.2020.05.004

Buckner, J. H., Chowell, G., \& Springborn, M. R. (2021). Dynamic prioritization of COVID-19 vaccines when social distancing is limited for essential workers. Proceedings of the National Academy of Sciences, 118(16), e2025786118. https://doi.org/10.1073/pnas.2025786118

Cao, Y., \& Li, H. (2021). Harmony between humanity and nature: Natural Vs. synthetic drug preference in Chinese atheists and Taoists. Journal of Religion and Health. https://doi.org/10.1007/ s10943-021-01314-6

Cao, Y., \& Li, H. (2022). Toward controlling of a pandemic: How self-control ability influences willingness to take the COVID-19 vaccine. Personality and Individual Differences, 188, 111447. https:// doi.org/10.1016/j.paid.2021.111447

Colzato, L. S., van Beest, I., van den Wildenberg, W. P., Scorolli, C., Dorchin, S., Meiran, N., Borghi, A. M., \& Hommel, B. (2010). God: Do i have your attention? Cognition, 117(1), 87-94. https://doi.org/ 10.1016/j.cognition.2010.07.003

Cronbach, L. J., \& Meehl, P. E. (1955). Construct validity in psychological tests. Psychological Bulletin, 52, 281-302. https://doi.org/10.1037/h0040957

Deopa, N., \& Fortunato, P. (2021). Coronagraben in Switzerland: Culture and social distancing in times of COVID-19. Journal of Population Economics, 34(4), 1355-1383. https://doi.org/10.1007/ s00148-021-00865-y

Driggin, E., Madhavan, M. V., Bikdeli, B., Chuich, T., Laracy, J., Biondi-Zoccai, G., Brown, T. S., Der Nigoghossian, C., Zidar, D. A., Haythe, J., Brodie, D., Beckman, J. A., Kirtane, A. J., Stone, G. W., Krumholz, H. M., \& Parikh, S. A. (2020). Cardiovascular considerations for patients, health care workers, and health systems during the COVID-19 pandemic. Journal of the American College of Cardiology, 75(18), 2352-2371. https://doi.org/10.1016/j.jacc.2020.03.031

Geertz, C. (1966). Religion as a cultural system. In M. Banton (Ed.), Anthropological approaches to the study of religion (pp. 1-46). Tavistock.

Greer, S. L., King, E. J., da Fonseca, E. M., \& Peralta-Santos, A. (2020). The comparative politics of COVID-19: The need to understand government responses. Global Public Health, 15(9), 14131416. https://doi.org/10.1080/17441692.2020.1783340

Hill, T. D., Gonzalez, K., \& Burdette, A. M. (2020). The blood of christ compels them: State religiosity and state population mobility during the Coronavirus (COVID-19) pandemic. Journal of Religion and Health, 59(5), 2229-2242. https://doi.org/10.1007/s10943-020-01058-9

Hofstede, G. (2001). Culture's consequences, comparing values, behaviors, institutions, and organizations across nations. Sage Publications.

Huang, F., Ding, H., Liu, Z., Wu, P., Zhu, M., Li, A., \& Zhu, T. (2020). How fear and collectivism influence public's preventive intention towards COVID-19 infection: A study based on big data from the social media. BMC Public Health, 20(1), 1-9. https://doi.org/10.1186/s12889-020-09674-6

Humphreys, C. (2005). A popular dictionary of Buddhism. Routledge.

Huynh, T. L. D. (2020). Does culture matter social distancing under the COVID-19 pandemic? Safety Science, 130, 104872. https://doi.org/10.1016/j.ssci.2020.104872

Jackson, J. C., \& Gray, K. (2019). When a good god makes bad people: Testing a theory of religion and immorality. Journal of Personality and Social Psychology, 117(6), 1203-1230. https://doi.org/10. 1037/pspp0000206

Lee, M., Lim, H., Xavier, M. S., \& Lee, E. Y. (2021). "A Divine Infection”: A systematic review on the roles of religious communities during the early stage of COVID-19. Journal of Religion and Health. https://doi.org/10.1007/s10943-021-01364-w

Li, H. (2021a). Follow or not follow?: The relationship between psychological entitlement and compliance with preventive measures to the COVID-19. Personality and Individual Differences, 174, 110678. https://doi.org/10.1016/j.paid.2021.110678

Li, H. (2021b). Time heals all wounds: Analysis of changes in temporal focus and implicit space-time mappings among survivors of the 2019 China earthquake over time. Language and Cognition, 13(4), 595-612. https://doi.org/10.1017/langcog.2021.14

Li, H., \& Cao, Y. (2018). Karma or immortality: Can religion influence space-time mappings? Cognitive Science, 42(3), 1041-1056. https://doi.org/10.1111/cogs.12579 
Li, H., \& Cao, Y. (2019). Hands occupied: Chinese farmers use more non-manual pointing than herders. Lingua, 222, 1-9. https://doi.org/10.1016/j.lingua.2019.02.006

Lu, J. G., Jin, P., \& English, A. S. (2021). Collectivism predicts mask use during COVID-19. In Proceedings of the National Academy of Sciences, 118(23), e2021793118. Doi: https://doi.org/10.1073/ pnas.2021793118

Ludeke, S. G., Vitriol, J. A., Larsen, E. G., \& Gensowski, M. (2021). Personality in a pandemic: Social norms moderate associations between personality and social distancing behaviors. Personality and Individual Differences, 177, 110828. https://doi.org/10.1016/j.paid.2021.110828

Murphy, K., Williamson, H., Sargeant, E., \& McCarthy, M. (2020). Why people comply with COVID-19 social distancing restrictions: Self-interest or duty? Australian \& New Zealand Journal of Criminology, 53(4), 477-496.

Nisbett, R. E., \& Miyamoto, Y. (2005). The influence of culture: Holistic versus analytic perception. Trends in Cognitive Sciences, 9(10), 467-473. https://doi.org/10.1016/j.tics.2005.08.004

Nongbri, B. (2013). Before religion. Yale University Press.

Oyserman, D., Coon, H. M., \& Kemmelmeier, M. (2002). Rethinking individualism and collectivism: evaluation of theoretical assumptions and meta-analyses. Psychological Bulletin, 128(1), 3-72. https://doi.org/10.1037/0033-2909.128.1.3

Paglieri, F., Borghi, A. M., Colzato, L. S., Hommel, B., \& Scorolli, C. (2013). Heaven can wait. How religion modulates temporal discounting. Psychological Research, 77(6), 738-747. https://doi.org/ 10.1111/cogs. 12579

Pichon, I., Boccato, G., \& Saroglou, V. (2007). Nonconscious influences of religion on prosociality: A priming study. European Journal of Social Psychology, 37(5), 1032-1045. https://doi.org/10.1002/ ejsp. 416

Quadri, S. A. (2020). COVID-19 and religious congregations: Implications for spread of novel pathogens. International Journal of Infectious Diseases, 96, 219-221. https://doi.org/10.1016/j.ijid.2020. 05.007

Richardson, P., \& Mueller, C. M. (2019). Moving yet being still: Exploring source domain reversal and force in explanations of enlightenment. Language and Cognition, 11(2), 310-339. https://doi.org/ 10.1017/langcog.2019.19

Rinpoche, D., Dorje, G., \& Kapstein, M. (1991). The Nyingma school of Tibetan Buddhism: Its fundamentals and history. Wisdom Publications.

Shariff, A. F., \& Norenzayan, A. (2011). Mean gods make good people: Different views of God predict cheating behavior. The International Journal for the Psychology of Religion, 21(2), 85-96. https:// doi.org/10.1080/10508619.2011.556990

Shen, M., Zu, J., Fairley, C. K., Pagán, J. A., An, L., Du, Z., Guo, Y., Rong, L., Xiao, Y., Zhuang, G., Li, Y., \& Zhang, L. (2021). Projected COVID-19 epidemic in the United States in the context of the effectiveness of a potential vaccine and implications for social distancing and face mask use. Vaccine, 39(16), 2295-2302. https://doi.org/10.1016/j.vaccine.2021.02.056

Sherab, K. P., \& Dongyal, K. T. (2010). The Buddhist path: A practical guide from the Nyingma tradition of Tibetan Buddhism. Shambhala Publications.

Susskind, D., \& Vines, D. (2020). The economics of the COVID-19 pandemic: an assessment. Oxford Review of Economic Policy, 36(Supplement_1), S1-S13. https://doi.org/10.1093/oxrep/graa036

Takano, Y., \& Osaka, E. (1999). An unsupported common view: Comparing Japan and the US on individualism/collectivism. Asian Journal of Social Psychology, 2(3), 311-341. https://doi.org/10.1111/ 1467-839X.00043

Tarakeshwar, N., Stanton, J., \& Pargament, K. I. (2003). Religion: An overlooked dimension in crosscultural psychology. Journal of Cross-Cultural Psychology, 34(4), 377-394. https://doi.org/10.1177/ 0022022103034004001

Triandis, H. C. (1999). Cross-cultural psychology. Asian Journal of Social Psychology, 2(1), 127-143. https://doi.org/10.1111/1467-839X.00029

Triberti, S., Durosini, I., \& Pravettoni, G. (2021). Social distancing is the right thing to do: Dark Triad behavioral correlates in the COVID-19 quarantine. Personality and Individual Differences, 170, 110453. https://doi.org/10.1016/j.paid.2020.110453

Uskul, A. K., Kitayama, S., \& Nisbett, R. E. (2008). Ecocultural basis of cognition: Farmers and fishermen are more holistic than herders. Proceedings of the National Academy of Sciences, 105(25), 8552-8556. https://doi.org/10.1073/pnas.0803874105

Vishkin, A. (2021). Variation and consistency in the links between religion and emotion regulation. Current Opinion in Psychology, 40, 6-9. https://doi.org/10.1016/j.copsyc.2020.08.005 
Vishkin, A., Bloom, P. B. N., Arikan, G., \& Ginges, J. (2021). A motivational framework of religion: Tying together the why and the how of religion. European Journal of Social Psychology. https://doi. org/10.1002/ejsp.2826

Wang, F. (2016). Geo-architecture and landscape in China's geographic and historic context (Vol. 4). Springer.

Wildman, W. J., Bulbulia, J., Sosis, R., \& Schjoedt, U. (2020). Religion and the COVID-19 pandemic. Religion, Brain and Behavior, 10(2), 115-117. https://doi.org/10.1080/2153599X.2020.1749339

Wuthnow, R. (2007). Cognition and religion. Sociology of Religion, 68(4), 341-360. https://doi.org/10. 1093/socrel/68.4.341

Xie, K., Liang, B., Dulebenets, M. A., \& Mei, Y. (2020). The impact of risk perception on social distancing during the COVID-19 pandemic in China. International Journal of Environmental Research and Public Health, 17(17), 6256. https://doi.org/10.3390/ijerph17176256

Publisher's Note Springer Nature remains neutral with regard to jurisdictional claims in published maps and institutional affiliations. 